\title{
LONGITUDINAL ACCELERATION MODELS FOR HORIZONTAL REVERSE CURVES OF TWO-LANE RURAL ROADS
}

\section{TOMÁS ECHAVEGUREN ${ }^{1 *}$, CRISTIAN HENRÍQUEZ ${ }^{2}$, GUSTAVO JIMÉNEZ-RAMOS ${ }^{3}$ \\ ${ }^{1,2,3}$ Civil Engineering Department, Engineering Faculty, Universidad de Concepción, Concepción, Chile}

Submitted 2 May 2019; accepted 6 December 2019

\begin{abstract}
The operating speed profile models adopt acceleration and deceleration as constant values obtained from kinematic models, assuming that the operating speeds between two consecutive sections are not spatially correlated. Existent research shows that acceleration and deceleration in horizontal reverse curves (HRC) depend on the tangent length and curve radii. In this paper, accelerations/decelerations-geometry models for light cars are proposed. The models are based on the data obtained in-field with a $10 \mathrm{~Hz}$ GPS under favourable traffic, weather, and pavement condition to isolate the effect of road geometry over the speed changes. The models were calibrated using the $95^{\text {th }}$ percentile of acceleration probability density function (pdf) obtained section to section in the HRC. It was found that the acceleration and deceleration pdf follow the Burr distribution. Therefore, a Box-Cox transformation is needed to properly calibrate acceleration-geometry models. The models obtained confirmed that accelerations and decelerations depend on the radius of entrance and departure curves of the HRC. The results contribute to better
\end{abstract}

* Corresponding author. E-mail: techaveg@udec.cl

Tomás ECHAVEGUREN (ORCID iD 0000-0003-1632-5988)

Cristian HENRÍQUEZ (ORCID iD 0000-0002-9676-3613)

Gustavo JIMÉNEZ-RAMOS (ORCID iD 0000-0002-7346-2586)

Copyright (C) 2020 The Author(s). Published by RTU Press

This is an Open Access article distributed under the terms of the Creative Commons Attribution License (http://creativecommons.org/licenses/by/4.0/), which permits unrestricted use, distribution, and reproduction in any medium, provided the original author and source are credited. 
understanding of the acceleration/deceleration patterns of light cars and to enhancing operating speed models in the HRC.

Keywords: acceleration/deceleration rate, horizontal reverse curves, light cars, longitudinal acceleration-geometry models, two-lane rural highways.

\section{Introduction}

The horizontal reverse curves, or "S-shaped curves", consist of the curves to the left or to the right followed by a curve in the opposite direction connected by a tangent, which eventually has a null length. According to FHWA (2009), the term is used in its abbreviated form as HRC. A safe geometric design should ensure that the operating speed along the HRC be homogeneous, avoiding excessive accelerations or decelerations that could destabilize the vehicles, provoking accidents. The operating speed profile is a tool to help designers to assess the homogeneity of speed during the geometrical design, which estimates the change in the operating speed along the HRC in terms of their geometry.

The simplest operating speed profile assumes that the operating speed is constant inside the horizontal curves and the acceleration or deceleration is constant outside them. Under this premise, the speed transition is currently estimated using kinematic relationships assuming that the so-called "operating acceleration" and "operating deceleration" are constant, which depends on the difference in the $85^{\text {th }}$ percentile of speed on a known length. Thus, the speed profile is idealized as speed reduction from the entrance tangent to the first curve and speed increase when the driver departs the curve, accelerating to the maximum speed at the intermediate tangent, decelerating again when entering the second curve and accelerating during the departure from the second curve (Figueroa and Tarko, 2007; Montella, Pariota, Galante, Imbriani, \& Mauriello, 2014).

Altamira, García, Echaveguren, and Marcet (2014) analysed the limitation of this approach in estimating operating speed profile models, particularly in the treatment of acceleration values and the length needed to accelerate or decelerate. Having analysed the respective literature, Altamira et al. (2014) found the values of acceleration between $0.2 \mathrm{~m} / \mathrm{s}^{2}$ and $1.18 \mathrm{~m} / \mathrm{s}^{2}$ and values of deceleration between $0.0 \mathrm{~m} / \mathrm{s}^{2}$ to $1.47 \mathrm{~m} / \mathrm{s}^{2}$. They also obtained strong relationship between the speed changes and the longitudinal slope, the curve radii, the entrance tangent length and the speed at the entrance tangent. They concluded that single values of accelerations and decelerations are not useful to enhance the operating speed profiles and that it is better to develop models that correlate acceleration/deceleration with the HRC geometry. 
Another aspect discussed by Altamira et al. (2014) was how to estimate the operating acceleration/deceleration. Some authors adopt this term to denote the $85^{\text {th }}$ percentile of the acceleration/deceleration using the $85^{\text {th }}$ percentiles of speed variation between two consecutive sections of a road. Altamira et al. (2014) estimated that the probability density function (pdf) of accelerations/decelerations is asymmetrical and that small changes in the acceleration/deceleration percentile imply large changes in the acceleration/deceleration values. Therefore, it is not feasible to estimate the acceleration/deceleration using the $85^{\text {th }}$ percentiles of speed variation.

The aim of this paper is to propose acceleration/decelerationgeometry models for light cars in the HRC of two-lane rural roads, based on the data obtained with GPS. The paper is structured as follows: the first part describes the existent acceleration-geometry models, including parameters, assumptions, and in-field measurement methods. In the second part, the authors describe the in-field data collection procedure used for obtaining geometric and kinematic parameters. In the next part, data processing and analysis are discussed, including the acceleration/deceleration patterns as well as the coupling of these data with road geometry. In the last part of the paper, the authors explain the calibration procedure, demonstrate the calibrated and validated models, and present conclusions of the research.

\section{Acceleration and deceleration modelling in horizontal curves}

\subsection{The concept of acceleration and deceleration}

Acceleration and deceleration are vectors with a certain magnitude that can be decomposed into the longitudinal and lateral components. The longitudinal component predominates in vehicles that move along straight segments of roads and the lateral component predominates in vehicles that move along horizontal curves. Under the assumption of constant acceleration, the kinematic law of Eq. (1) permitted to obtain the speed change between two consecutive sections of a road. In Eq. (1), $a_{i, i+1}$ is the speed change in $\mathrm{m} / \mathrm{s}^{2}, V_{i, i+1}$ are speeds in $\mathrm{km} / \mathrm{h}$ in sections " $i$ " and " $i+1$ ", respectively, " $L$ " is the length between sections " $i$ " and " $i+1$ " in $\mathrm{m}$, and 29.92 is a constant for unit homogeneity.

$$
a_{i, i+1}=\frac{V_{i}^{2}-V_{i+1}^{2}}{25.92 L} .
$$


Several authors have criticized this model used to estimate the longitudinal acceleration based in the operating speed (expressed as the $85^{\text {th }}$ percentile of speed pdf $\left(V_{85}\right)$ ) of Eq. (1). Bella (2013) and Pérez, García, Torregrosa, and D'Attoma (2010) concluded that the use of $V_{85}$ in Eq. (1) underestimates the actual values of acceleration and deceleration. Similar results were obtained by Crisman, Perco, Robba, and Roberti (2007). Park and Saccomano (2006) argued that the speed pdf between two consecutive points are not necessarily statistically independent. If both sections are close enough, the covariance is not zero and if Eq. (1) is used, the speed change is underestimated. Crisman et al. (2007), Bella (2013) and Altamira et al. (2014) proved that the pdf of acceleration and deceleration are non-normal and are better described by asymmetrical pdf, which are also different if they are obtained at the entrance tangent, inside the curve, or at the starting/ending points of the curves. Therefore, a precise definition of the "operating acceleration" (or deceleration) must include the random nature of the variable and the spatial correlation of speed, irrespective whether speed changes are inferred from speed measured, from operating speed, or measured directly.

\subsection{Acceleration and deceleration values used for speed profile modelling}

Table 1 summarizes the acceleration/deceleration values of light cars estimated by several authors for single horizontal curves. The dispersion of the values proposed by each author is caused by differences in data collection methods, estimation methods, local characteristics of drivers, road geometry and environment. Therefore, it is not advisable to use a unique and single value of acceleration and deceleration to estimate speed changes in speed profiles.

The acceleration/deceleration values given in Table 1 have limitations. Figueroa and Tarko (2007) found that the speed changes inside single horizontal curves depend on the vehicle characteristics and on the deflection angle of the curve. Fitzpatrick et al. (2001), Echaveguren and Basualto (2003), Perco and Robba (2005) and Altamira et al. (2014) established that the speed change depends on the curve radius and that it varies according to the tangent length. Echaveguren, Díaz, and Vargas-Tejeda (2015) verified that speed changes between the tangent before the first curve of an HRC and inside the curve are not homogeneous, therefore, deceleration is not constant. Fitzpatrick et al. (2001) and Crisman, Marchionna, Perco, Robba, and Roberti (2005) proposed that acceleration/deceleration values can be better estimated 
Table 1. Acceleration and deceleration values reported in the literature for single horizontal curves

\begin{tabular}{|c|c|c|c|}
\hline Author & $a, m / s^{2}$ & $d, \mathrm{~m} / \mathrm{s}^{2}$ & Comments \\
\hline $\begin{array}{l}\text { Fitzpatrick and Collins } \\
(2000)\end{array}$ & 0.54 & 1.00 & $\begin{array}{l}\text { Maximum acceleration: } 1.77 \mathrm{~m} / \mathrm{s}^{2} \\
\text { maximum deceleration: } 1.44 \mathrm{~m} / \mathrm{s}^{2}\end{array}$ \\
\hline $\begin{array}{l}\text { Echaveguren } \\
\text { and Basualto (2003) }\end{array}$ & 0.30 & 0.65 & Speed measured with a laser gun \\
\hline \multirow{2}{*}{ Perco and Robba (2005) } & - & 0.54 & $\begin{array}{l}\text { Deceleration estimated using mean } \\
\text { speed values }\end{array}$ \\
\hline & - & 0.71 & $\begin{array}{l}\text { Deceleration estimated using } \\
85^{\text {th }} \text { percentile of speed pdf }\end{array}$ \\
\hline Figueroa and Tarko (2007) & 0.49 & 0.73 & $\begin{array}{l}\text { Deceleration estimated using } \\
85^{\text {th }} \text { percentile of speed pdf }\end{array}$ \\
\hline Lamm et al. (2007) & 0.85 & 0.85 & Highest acceleration: $0.88 \mathrm{~m} / \mathrm{s}^{2}$ \\
\hline Yang and Hassan (2008) & 0.20 & 0.20 & $\begin{array}{l}\text { Values obtained for operating } \\
\text { speed }>70 \mathrm{~km} / \mathrm{h}\end{array}$ \\
\hline Dell'Acqua et al. (2008) & 0.60 & 0.71 & Speed measured with a laser gun \\
\hline Dell'Acqua and Russo (2010) & 0.68 & 0.70 & Speed measured with a laser detector \\
\hline Hu and Donnell (2010) & 1.46 & 1.49 & $\begin{array}{l}\text { Speed measured using GPS } \\
\text { at night }\end{array}$ \\
\hline \multirow[b]{2}{*}{ Bella (2014) } & $0.09-0.66$ & $0.08-1.45$ & $\begin{array}{l}\text { Speed values obtained using } \\
\text { the } 85^{\text {th }} \text { percentile of pdf }\end{array}$ \\
\hline & $0.26-0.84$ & $0.49-1.81$ & $\begin{array}{l}\text { Values obtained by direct } \\
\text { measurement of acceleration } \\
\text { and deceleration }\end{array}$ \\
\hline Altamira et al. (2014) & $0.10-0.20$ & $0.10-0.50$ & $\begin{array}{l}\text { Speed measured using GPS } \\
\text { at daytime }\end{array}$ \\
\hline Xu et al. (2017) & 0.59 & 0.84 & $\begin{array}{l}\text { Accelerations measured } \\
\text { with an accelerometer }\end{array}$ \\
\hline Xu et al. (2018) & 1.57 & 2.48 & $95^{\text {th }}$ percentile of acceleration pdf \\
\hline
\end{tabular}

using stratified values according to the curve radii. The concept, however, remains the same: in every curve, drivers reduce vehicle speed when entering the curve and increase vehicle speed when they leave the curve. Table 2 shows that speed change is higher for the smallest radii and lower for the largest radii, the possibility that the driver accelerates in the curves with large radii has not been considered. 
Table 2. Acceleration and deceleration values stratified according to the radius of single horizontal curves

\begin{tabular}{|c|c|c|c|c|}
\hline Authors & $a, \mathrm{~m} / \mathrm{s}^{2}$ & $d, m / s^{2}$ & Radius, m & Comments \\
\hline \multirow{6}{*}{$\begin{array}{l}\text { Fitzpatrick et al. } \\
\text { (2001) }\end{array}$} & 0 & - & $>875$ & \multirow{6}{*}{$\begin{array}{l}\text { Maximum acceleration: } 1.77 \mathrm{~m} / \mathrm{s}^{2} \\
\text { Maximum deceleration: } 1.44 \mathrm{~m} / \mathrm{s}^{2}\end{array}$} \\
\hline & 0.21 & - & $436 \leq R \leq 875$ & \\
\hline & 0.43 & - & $250 \leq R \leq 436$ & \\
\hline & 0.54 & - & $175<R \leq 250$ & \\
\hline & - & 0.00 & $>436$ & \\
\hline & - & 1.00 & $<175$ & \\
\hline \multirow{3}{*}{$\begin{array}{l}\text { Crisman et al. } \\
\text { (2005) }\end{array}$} & 0.54 & 1.00 & $\leq 178$ & \multirow{3}{*}{$\begin{array}{l}\text { Obtained using the } 85^{\text {th }} \text { percentile } \\
\text { of speed pdf }\end{array}$} \\
\hline & 0.43 & 0.50 & $178<R<437$ & \\
\hline & 0.20 & 0.20 & $437 \leq R \leq 2187$ & \\
\hline
\end{tabular}

\subsection{Acceleration and deceleration models dependent on the geometry}

Table 3 summarizes the acceleration/deceleration-geometry models for light cars, available for single horizontal curves. The authors obtained these models measuring speed, estimating the $85^{\text {th }}$ percentile of speed in different sections of the curves and using Eq. (1) to estimate acceleration and deceleration that they named $a_{85}$ and $d_{85}$, respectively.

Table 3. Summary of speed change models for single horizontal curves

\begin{tabular}{|c|c|c|c|c|}
\hline Author & Acceleration/deceleration models, $\mathrm{m} / \mathrm{s}^{2}$ & Radius, m & $R^{2}$ & Comments \\
\hline 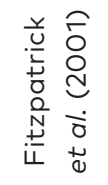 & $d_{85}=0.6749-\frac{295.14}{R}$ & $175-436$ & 0.48 & $\begin{array}{l}d_{85}=0, R \geq 436 \mathrm{~m} \\
d_{85}=1, R<175 \mathrm{~m}\end{array}$ \\
\hline \multirow{2}{*}{ 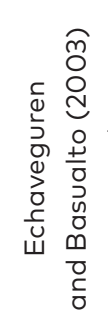 } & $d_{85}=\frac{131.418}{R}$ & \multirow[b]{2}{*}{$250-436$} & 0.63 & $\begin{array}{l}\text { First half of the curve: } \\
d_{85}=-0.55, R<250 \mathrm{~m} \\
d_{85}=-0.24, R>436 \mathrm{~m}\end{array}$ \\
\hline & $a_{85}=\frac{52.524}{R}$ & & 0.82 & $\begin{array}{l}\text { Second half } \\
\text { of the curve: } \\
\begin{array}{l}a_{85}=0.21, R<250 \mathrm{~m} \\
a_{85}=0.06, R>436 \mathrm{~m}\end{array}\end{array}$ \\
\hline
\end{tabular}




\begin{tabular}{|c|c|c|c|c|}
\hline Author & Acceleration/deceleration models, $\mathrm{m} / \mathrm{s}^{2}$ & Radius, m & $R^{2}$ & Comments \\
\hline \multirow{2}{*}{ 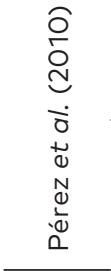 } & $d_{85}=0.24+0.0015 C C R$ & $80-930$ & 0.71 & \multirow{2}{*}{$\begin{array}{l}\text { Models calibrated } \\
\text { at the entrance tangent } \\
\text { to the curve }\end{array}$} \\
\hline & $d_{85}=0.264+\frac{67.80}{R}$ & $80-930$ & 0.70 & \\
\hline 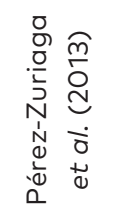 & $d_{85}=0.447+\frac{90.472}{R}$ & $52-519$ & 0.68 & $\begin{array}{l}\text { Models calibrated } \\
\text { at the entrance tangent } \\
\text { to the curve }\end{array}$ \\
\hline \multirow{2}{*}{ 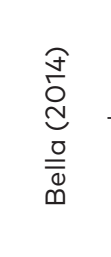 } & $d_{85}=-1.316+\frac{148.28}{R}+0.015 V_{85 \max }$ & $150-800$ & 0.59 & \multirow{2}{*}{$\begin{array}{l}\text { Models calibrated } \\
\text { in a driving simulator } \\
\text { for the first half } \\
\text { of the curve }\left(d_{85}\right) \\
\text { and second half } \\
\text { of the curve }\left(a_{85}\right) \text {. }\end{array}$} \\
\hline & $a_{85}=-0.567+\frac{74.47}{R}+0.007 V_{85 \max }$ & $150-800$ & 0.54 & \\
\hline \multirow{2}{*}{ 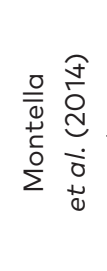 } & $d_{85}=0.277+\frac{0.098}{R}-0.0017 C C R_{2}+0.037 G u$ & $250-2775$ & 0.40 & \multirow{2}{*}{$\begin{array}{l}a_{85} \text { and } d_{85} \text { were } \\
\text { obtained using } \\
\text { the pdf of individual } \\
\text { acceleration } \\
\text { and deceleration values } \\
\text { obtained in-field }\end{array}$} \\
\hline & $a_{85}=0.159+\frac{0.035}{R}+0.025 G d-0.027 G u$ & $250-2775$ & 0.40 & \\
\hline \multirow{2}{*}{ 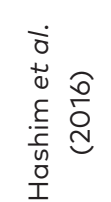 } & $a_{85}=-0.211+\frac{6.32}{\sqrt{R}}$ & $59-823$ & 0.53 & \multirow{2}{*}{$\begin{array}{l}\text { Models calibrated } \\
\text { at the entrance tangent } \\
\text { to the curve }\end{array}$} \\
\hline & $d_{85}=-0.374+\frac{12.52}{\sqrt{R}}$ & $59-823$ & 0.56 & \\
\hline
\end{tabular}

$R$ : radius, in $m_{;} V_{85 \max }$ : maximum operating speed at the entrance or exit tangent, in $\mathrm{km} / \mathrm{h} ; \omega$ : deflection angle, in grad; $L_{c}$ : curve length, in $\mathrm{km} ; C C R_{2}$ : curvature change ratio of the $2 \mathrm{~km}$ preceding curve, in gon/km; Gd: equivalent downgrade, in \%; Gu: equivalent upgrade, in \%.

The majority of models used only radius as a geometric explanatory variable. Bella (2013) recognized the effect of the operating speed before and after the curve, Montella et al. (2014) included the effect of vertical geometry. Altamira et al. (2014) found that the magnitude of acceleration and deceleration depends also on the operating speed of drivers at 
the time and distance at which they discover the curve, and that this distance is the actual deceleration length. At the end of the curve, the pattern described by Altamira et al. (2014) is as follows: if drivers have sufficient visibility, the acceleration distance is limited by the sight distance. These findings are consistent with the results and models obtained by Bella (2013) and Montella et al. (2014).

\section{Data collection}

The collected data are composed of two datasets. The first one included the geometry of the HRC and the second one - the position, speed and longitudinal acceleration data of light vehicles measured at each HRC. Both data sets were obtained previously by Echaveguren et al. (2015) in the Chilean two-lane rural roads by using the car following procedure.

The geometric dataset was obtained using satellite images and heading readings of a GSP logger, which was used to estimate the curvature radius $\left(R_{i}\right)$, deflection angles $\left(\omega_{i}\right)$ curve lengths $\left(L_{c i}\right)$ and tangent lengths of the geometric configuration given in Figure 1. Table 4 summarizes the geometric characteristics of the HRC measured by Echaveguren et al. (2015).

The second dataset consists of the kinematic variables used to elaborate the models: position, heading, speed and acceleration (deceleration is recorded as negative acceleration) obtained in 23 HRC, considering 20 runs per curve (Echaveguren et al. 2015).

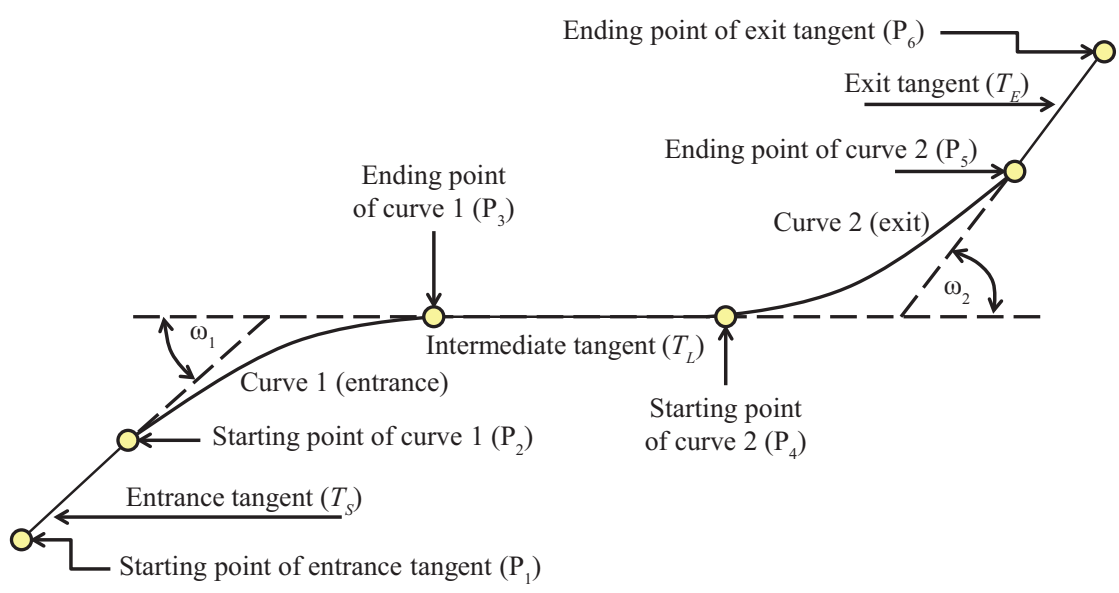

Figure 1. Geometric configuration of the HRC used by Echaveguren et al. (2015) 
Table 4. Geometric characteristics of HRC measured by Echaveguren et al. (2015)

\begin{tabular}{|c|c|c|c|c|c|c|c|}
\hline $\begin{array}{l}\text { \# of } \\
\text { HRC }\end{array}$ & $R_{1}, \mathrm{~m}$ & $\omega_{1}$, grad & $L_{c 1}, m$ & $T_{L,} \mathrm{~m}$ & $R_{2}, \mathrm{~m}$ & $\omega_{2}, g$ & $L_{c 2}, \mathrm{~m}$ \\
\hline 1 & 457 & 45.8 & 328.6 & 677.4 & 457 & 53.3 & 382.8 \\
\hline 2 & 457 & 53.3 & 382.8 & 677.4 & 457 & 45.8 & 328.6 \\
\hline 3 & 627 & 40.9 & 402.2 & 717.9 & 509 & 46.9 & 374.8 \\
\hline 4 & 509 & 46.9 & 374.8 & 717.9 & 627 & 40.9 & 402.2 \\
\hline 5 & 455 & 29.0 & 207.6 & 479.3 & 223 & 45.2 & 157.7 \\
\hline 6 & 222 & 45.2 & 157.7 & 479.3 & 455 & 29.1 & 207.6 \\
\hline 7 & 488 & 38.6 & 295.7 & 970.9 & 466 & 17.7 & 129.3 \\
\hline 8 & 466 & 17.7 & 129.3 & 970.9 & 488 & 38.6 & 295.7 \\
\hline 9 & 340 & 36.2 & 193.7 & 113.0 & 312 & 43.3 & 212.1 \\
\hline 10 & 312 & 43.3 & 212.1 & 113.0 & 340 & 36.2 & 193.7 \\
\hline 11 & 223 & 106.2 & 371.4 & 224.0 & 193 & 89.1 & 270.0 \\
\hline 12 & 330 & 40.8 & 211.6 & 681.0 & 193 & 89.1 & 270.0 \\
\hline 13 & 193 & 89.1 & 270.0 & 224.0 & 223 & 106.2 & 371.4 \\
\hline 14 & 190 & 47.2 & 141.2 & 86.8 & 190 & 32.4 & 96.8 \\
\hline 15 & 190 & 32.4 & 96.9 & 86.8 & 190 & 47.2 & 141.2 \\
\hline 16 & 686 & 17.7 & 190.9 & 1340.7 & 686 & 19.2 & 207.3 \\
\hline 17 & 686 & 19.2 & 207.3 & 1340.7 & 686 & 17.7 & 190.8 \\
\hline 18 & 517 & 47.1 & 382.1 & 607.3 & 677 & 16.9 & 179.1 \\
\hline 19 & 327 & 51.9 & 267.1 & 434.0 & 446 & 41.4 & 290.5 \\
\hline 20 & 402 & 45.4 & 286.3 & 176.9 & 446 & 40.9 & 286.6 \\
\hline 21 & 253 & 59.6 & 236.7 & 259.6 & 357 & 50.4 & 282.7 \\
\hline 22 & 355 & 46.4 & 258.9 & 225.4 & 192 & 77.4 & 234.1 \\
\hline 23 & 192 & 77.4 & 234.1 & 225.4 & 355 & 46.4 & 258.9 \\
\hline
\end{tabular}

To avoid the bias induced by the factors other than horizontal geometry, Echaveguren et al. (2015) collected the data considering the following conditions: a) environment conditions: the data were collected during the daytime, at dry conditions and clear day; b) traffic conditions: the data were obtained in test sections with low traffic volume (AADT < 5000 vehicles per day-year); c) road geometry: flat terrain $(i<4 \%)$, cross section with a width of $7 \mathrm{~m}$ and shoulders with a width of $0.5 \mathrm{~m}$ were considered. Road geometry was obtained by in-field measurements; d) pavement condition: only paved roads with
Longitudinal

Acceleration Models for Horizontal

Reverse Curves of Two-Lane Rural

RoadsLanes of Road Intersections 
good pavement condition were considered. These data were obtained by in-field pavement inspection.

Position, heading, speed and acceleration were obtained with a $10 \mathrm{~Hz}$ GPS logger, using the procedure of car following tested and implemented by Arellano, Echaveguren, and Vargas-Tejeda (2015). The GPS logger collects the data each 0.1 second, with a precision of $0.05 \%$ for distance, $0.2 \mathrm{~km} / \mathrm{h}$ for speed, $0.1^{\circ}$ for heading, $1.0 \%$ for acceleration, and $3 \mathrm{~cm}$ for position (Arellano et al. 2015). A relevant feature of the GPS logger is its capability to obtain longitudinal acceleration directly, avoiding indirect estimations using Eq. (1).

\section{Data processing}

Data processing was performed in four steps. In the first step, the raw data were filtered using the Kalman filter implemented in the software of the GPS logger. The Kalman filter allows erasing the dropouts and coupling the position, speed and acceleration data. The second step was to export the data from the GPS logger used to obtain a data set of position, heading, speed and longitudinal acceleration data each 0.1 second and each $1 \mathrm{~m}$. The third step was to integrate the data of each run in a single database with a common and unique starting point and to erase the starting and ending data in the transition segment at which the probe vehicle stabilizes its speed and its distance to the vehicle followed. The fourth step was to integrate this data base into the geometric data set, obtaining a unique and single database for analysis and modelling.

\section{Data analysis}

Data analysis included the study of acceleration pdf at several points of the HRC, comparison of the values of the $85^{\text {th }}$ percentile of the acceleration pdf with the so-called $85^{\text {th }}$ percentile of acceleration obtained using Eq. (1), and the study of the effect of geometry over the acceleration values and acceleration profile. The measured acceleration profile at each HRC contains between 1000 and 3000 data points per run, depending on the HRC length and the speed (data obtained each 0.1 second). Thus, the HRC was discretized in several cross sections at which a set of acceleration data points was clustered. The procedure used to accomplish this task was the following: The HRC was discretized in cross sections each $100 \mathrm{~m}$, except the curves and $T_{c}$, which were discretizes in 4 segments and in 2 segments respectively (Figure 2). At each cross section in both sides a set of 50 speed data points was taken to avoid overlapping. It was verified 
whether the pdf was uniform in order to ensure that the speed does not change and the acceleration remains approximately constant around the cross section. The procedure was repeated reducing the distance between cross sections to obtain denser discretization. The procedure was applied to each HRC and each run. Each cross section finally contained 41 data points grouped. At each cross section, all runs were coupled, obtaining a total of 820 acceleration data points.

A goodness of fit (GOF) test was applied to each set of acceleration data associated with the cross sections featured in Figure 2 in each HRC to identify the pdf of the curves. The GOF test was performed using the EasyFit $\AA$ software. The pdf with the best fit was the Burr's pdf (also known as Singh-Maddala or Burr Type III pdf). Similar result was obtained by Altamira et al. (2014) for single horizontal curves. The Burr's pdf is flexible enough to be fitted to different levels of kurtosis and asymmetry changing only the parameters of shape, scale and location. This property is particularly relevant in observing the changes of the pdf section by section along the HRC and in estimating percentiles of acceleration avoiding Eq. (1). A total of 320 pdf per HRC were obtained considering all the runs and cross sections shown in Figure 2. The following findings were made based on the analysis of acceleration patterns:

The $50^{\text {th }}, 60^{\text {th }}, 70^{\text {th }}, 80^{\text {th }}, 90^{\text {th }}, 95^{\text {th }}$ and $99^{\text {th }}$ percentiles of the acceleration pdf were compared with the acceleration obtained with Eq. (1) using the operating speed estimated at each cross section shown in Figure 2. The results showed that all acceleration/deceleration
Longitudinal

Acceleration Models for Horizontal

Reverse Curves of Two-Lane Rural RoadsLanes of Road Intersections

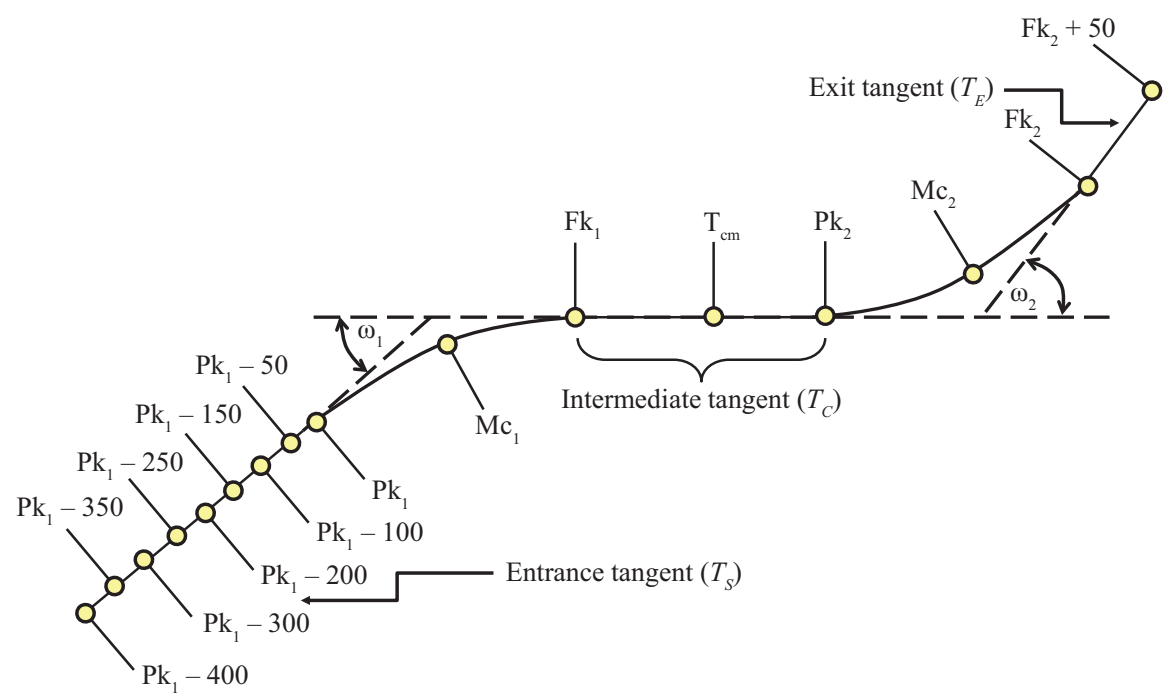

Figure 2. Segmentation of the HRC used for data analysis 
values obtained from the pdf were higher than those obtained using Eq. (1). It implies that the acceleration values obtained using Eq. (1) were lower than the $50^{\text {th }}$ percentile of acceleration, and that they largely underestimate the operating acceleration. Therefore, it is not recommended to use Eq. (1) to estimate longitudinal acceleration unless the speed values correspond to the individual data collected at a certain distance.

The pdf of acceleration/deceleration are non-normal and their kurtosis and skewness vary at each cross section. For HRC with sharp radii and short intermediate tangents, the pdf has positive skewness at the entrance tangent, negative skewness at the exit tangent and zero skewness between curves including the intermediate tangent.

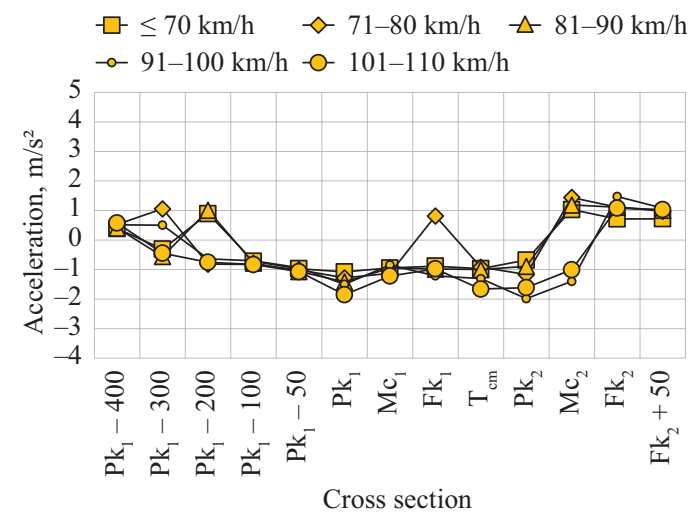

a) $R_{1}<200 \mathrm{~m}, R_{2}<200 \mathrm{~m} ; T_{L}<200 \mathrm{~m}$

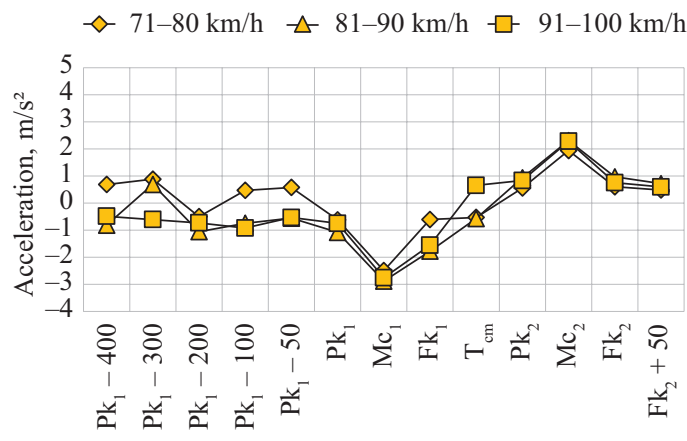

Cross section

c) $R_{1}<200 \mathrm{~m} ; 201<R_{2}<400 \mathrm{~m}$;

$201 \mathrm{~m}<T_{L}<400 \mathrm{~m}$

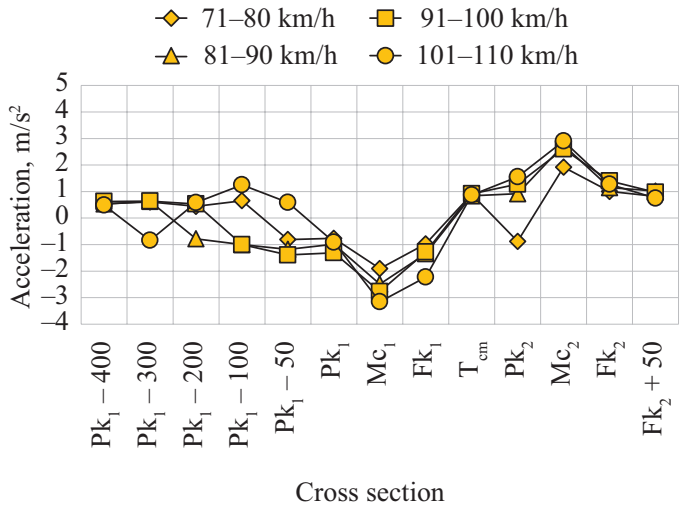

b) $R_{1}<200 \mathrm{~m}, R_{2}<200 \mathrm{~m} ; 201 \mathrm{~m}<T_{L}<400 \mathrm{~m}$

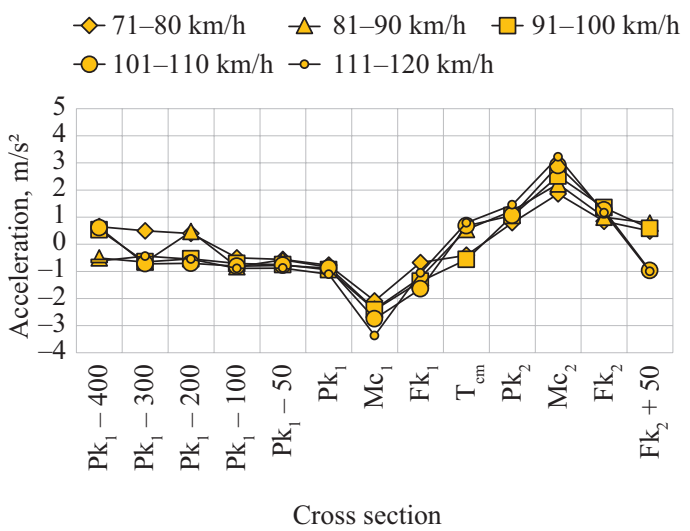

d) $201 \mathrm{~m}<R_{1}<400 \mathrm{~m} ; 201 \mathrm{~m}<R_{2}<400 \mathrm{~m}$;

$T_{L}<200 \mathrm{~m}$ 


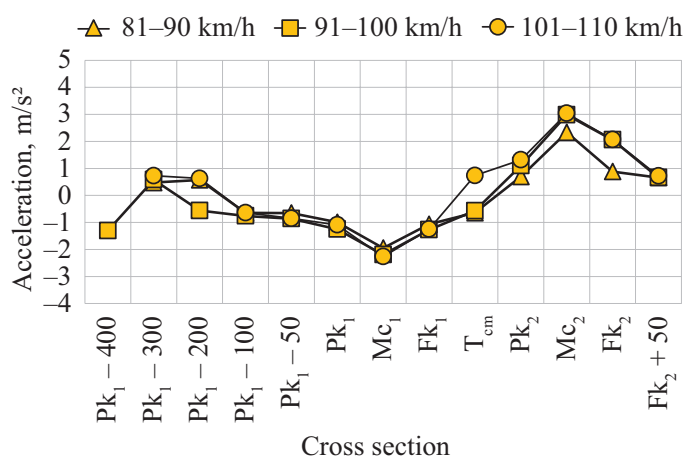

e) $201 \mathrm{~m}<R_{1}<400 \mathrm{~m} ; R_{2}<200 \mathrm{~m}$;

$201 \mathrm{~m}<T_{L}<400 \mathrm{~m}$

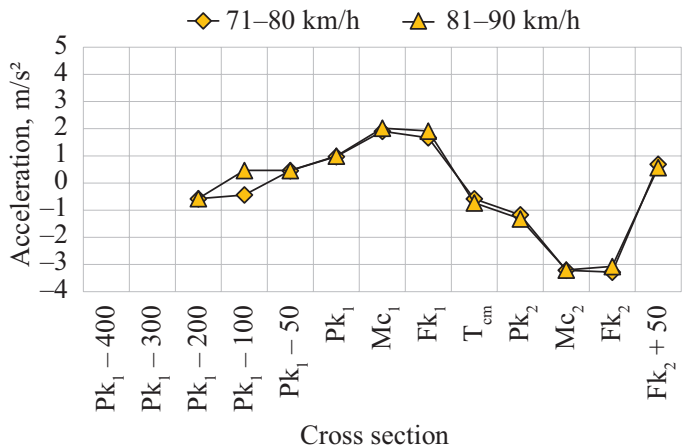

g) $201 \mathrm{~m}<R_{1}<400 \mathrm{~m} ; R_{2}<200 \mathrm{~m} ; T_{L}>400 \mathrm{~m}$

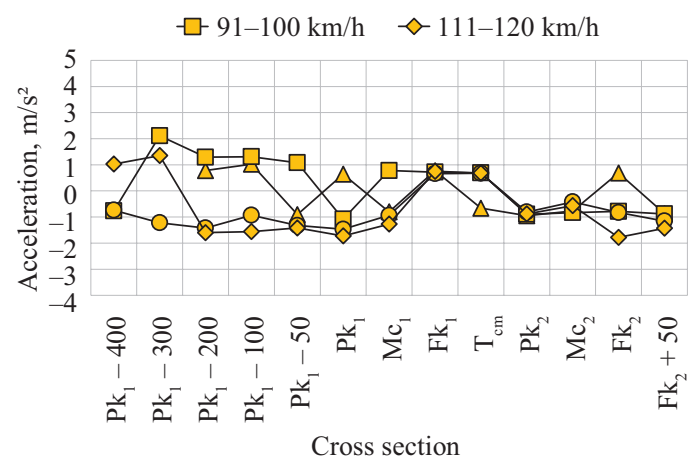

f) $201 \mathrm{~m}<R_{1}<400 \mathrm{~m} ; 201 \mathrm{~m}<R_{2}<400 \mathrm{~m}$; $201 \mathrm{~m}<T_{L}<400 \mathrm{~m}$

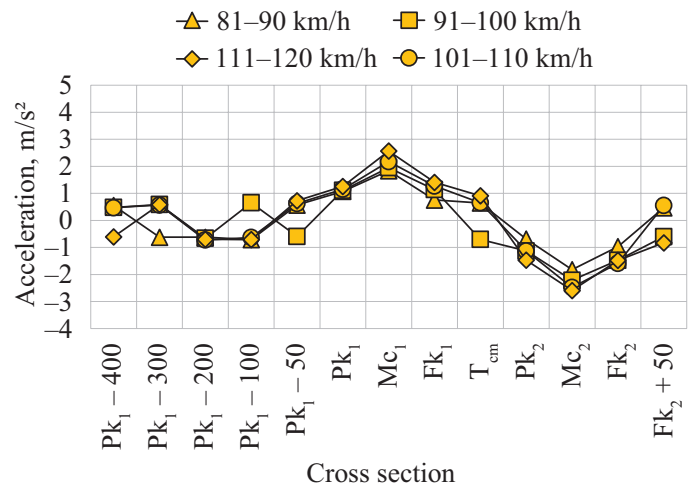

h) $201 \mathrm{~m}<R_{1}<400 \mathrm{~m} ; 201 \mathrm{~m}<R_{2}<400 \mathrm{~m}$; $T_{L}>400 \mathrm{~m}$

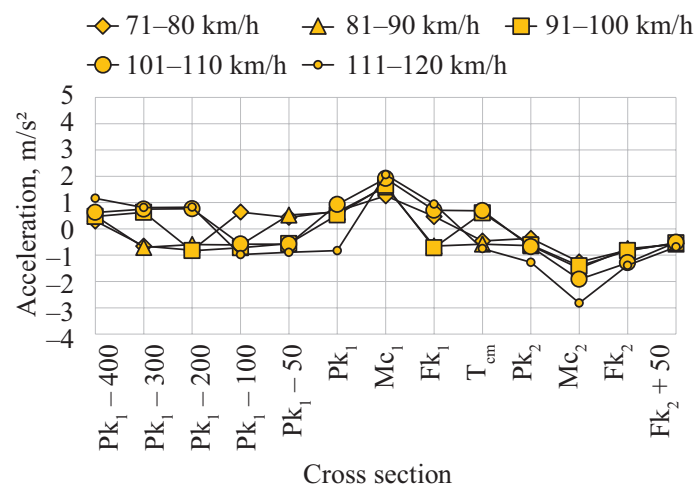

i) $R_{1}>400 \mathrm{~m} ; R_{2}>400 \mathrm{~m} ; T_{L}>400 \mathrm{~m}$

Figure 3. Acceleration profiles for diverse geometries of HRC using the $95^{\text {th }}$ percentile of acceleration 
For HRC with large radii and long intermediate tangents the pattern is similar, but at the intermediate tangent the pdf tends to be flatter (low kurtosis) than the others (with low kurtosis). For HRC with very large radius and intermediate tangents, the pdf tends to be similar. It means that the kurtosis and skewness remain similar at each cross section. This behaviour is relevant for modelling because the classical regression models are not valid for obtaining acceleration-geometry models that require additional statistical treatment of data.

Because of the skewness of the pdf it is not clear what is the best percentile of acceleration for describing the "operating acceleration". Small changes in the highest percentiles of pdf with negative skewness do not affect the acceleration values. In contrast, small change in the highest percentiles of pdf with positive skewness induces large change in the acceleration values. According to the behaviour of the pdf estimated, the $95^{\text {th }}$ percentile of acceleration pdf was considered.

Because the operating acceleration is obtained from a pdf and depends largely on the geometry, it is not recommended to provide typical values, stratified or not, according to the radius of curves. The operating acceleration values given in Table 1 show that in the first curve of the HRC it is possible to obtain "operating acceleration" stratified or not according to the radius, as shown in Figure 3. However, at the intermediate tangent and at the second curve of the HRC, the acceleration values largely depend on the geometry. It implies that the values proposed in the literature (Tables 1 and 2) are valid for single horizontal curves and could be valid for the entrance curve of the HRC, but not for the exit curve. Considering that the acceleration inside the first curve of the HRC depends also on the approach speed, this finding reinforces the need of using acceleration-geometry models instead of single acceleration values stratified or not by radius.

The last test was to study the acceleration/deceleration profiles with regard to the geometry of the HRC. The $95^{\text {th }}$ percentiles of acceleration obtained previously were clustered according the radius and tangent length and plotted separately according to the operating speed at the entrance tangent, as shown in Figure 3.

In Figure 3 four acceleration patterns are observed. In restrained geometries (Figure 3a), drivers tend to reduce speed, which results in uniform decelerations along Curve 1 and tangent, accelerating when driving along Curve 2. Similar behaviour is observed for geometric designs less restrained but homogeneous (Figure 3f). A more balanced geometry helps drivers to make more homogenous speed changes around zero deceleration, which means that operating speed remains constant in this type of geometry of the HRC. For radius up to $400 \mathrm{~m}$, drivers tend to decelerate when entering Curve 1 and to accelerate in the 
tangent and in Curve 2 (Figures 3b, 3c, 3d and 3e). Those patterns are similar for tangent lengths up to $400 \mathrm{~m}$. For designs with larger radii and tangents (Figures 3g, 3h and 3i), drivers tend to accelerate along Curve 1 and decelerate along the tangent until entering Curve 2. Exiting Curve 2, drivers tend to accelerate again. This behaviour is consistent with the fact that drivers appreciate a long tangent preceding the next curve.

\section{Calibration and validation of acceleration and deceleration models}

The calibration was performed using between $70 \%$ to $80 \%$ of the dataset, depending on the number of outliers erased. At the same time, the validation of models was performed using between $20 \%$ and $3 \%$ of the dataset. Because the symmetry of the acceleration pdf varies along the curve, the variance is not constant, violating the assumption of homoscedasticity and normality of the errors of linear models. To overcome this behaviour of the acceleration pdf, the Box-Cox transformation was applied to acceleration data. Eq. (2) shows the Box-Cox transformation model, in which $y_{i}$ represents the acceleration data, $\lambda_{1}$ and $\lambda_{2}$ are the parameter of the Box-Cox transformation. For the acceleration model $\lambda_{2}=0$, because $y_{i}$ is positive. For the deceleration model $\lambda_{2} \neq 0$ in order to ensure that the argument of $\log ()$ is higher than zero. A value of $\lambda_{2}=4$ was chosen taking into account the magnitude of the deceleration values.

$$
Y_{i}^{\left(\lambda_{1}, \lambda_{2}\right)}= \begin{cases}\frac{\left(y_{i}+\lambda_{2}\right)^{\lambda_{1}}-1}{\lambda_{1}} ; & \lambda_{1} \neq 0 ; \\ \log \left(y_{i}+\lambda_{2}\right) ; & \lambda_{1}=0 .\end{cases}
$$

Specifications of the linear model used are described by Eq. (3), in which $y_{i}$ represents the $95^{\text {th }}$ percentile of acceleration or deceleration, $\left(a_{95, i}\right.$ and $d_{85, i}$ in $\left.\mathrm{m} / \mathrm{s}^{2}\right), \beta_{i}$ are parameters of the model. The $x_{i}$ variables represent the $85^{\text {th }}$ percentile of speed at the entrance tangent $\left(V_{85 a}\right.$, in $\mathrm{km} / \mathrm{h})$, the $85^{\text {th }}$ percentile of speed at the point $\mathrm{P}_{i}$ of Figure $1\left(V_{85, \mathrm{P} i}\right.$, in $\mathrm{km} / \mathrm{h})$, the radius of each curve $\left(R_{i}\right.$ in $\left.\mathrm{m}\right)$, the deflection angle of each curve $\left(\omega_{i}\right.$ in grad), the curve length $\left(L_{c i}\right.$ in $\left.\mathrm{m}\right)$ and the tangent length $\left(L_{T}\right.$ in $\mathrm{m}$ ). The nomenclature of the calibrated models is shown in Table 5.

$$
Y_{i}^{\left(\lambda_{1}, \lambda_{2}\right)}=\beta_{0}+\sum_{i} \beta_{i} x_{i}
$$

The calibrated models are summarized in Tables 6 and 7, and the validation results in Table 8. The models described in Table 6 
Table 5. Nomenclature of the calibrated models

\begin{tabular}{|c|c|c|c|c|c|c|c|}
\hline \multirow{2}{*}{ Geometric entity } & \multirow{2}{*}{$\begin{array}{c}\text { Point } \\
\text { in Fig. } 1\end{array}$} & \multicolumn{3}{|c|}{ Radius, m } & \multicolumn{3}{|c|}{ Tangent length, m } \\
\hline & & 190-700 & 190-399 & 400-700 & $80-120$ & $170-260$ & $>400$ \\
\hline \multirow{3}{*}{ Curve 1} & $\mathrm{P}_{2}$ & M2-1 & M2-2 & $\mathrm{M} 2-3$ & - & - & - \\
\hline & $\mathrm{P}_{3}$ & M3-1 & M3-2 & M3-3 & - & - & - \\
\hline & $\mathrm{P}_{4}$ & M4-1 & M4-2 & M4-3 & - & - & - \\
\hline \multirow[t]{2}{*}{ Intermediate tangent } & $\mathrm{P}_{5}$ & - & - & - & M5-1 & M5-2 & M5-3 \\
\hline & $\mathrm{P}_{6}$ & M6-1 & M6-2 & M6-3 & - & - & - \\
\hline \multirow[t]{2}{*}{ Curve 2} & $\mathrm{P}_{7}$ & M7-1 & M7-2 & M7-3 & - & - & - \\
\hline & $\mathrm{P}_{8}$ & M8-1 & M8-2 & M8-3 & - & - & - \\
\hline
\end{tabular}

Table 6. Acceleration models calibrated

\begin{tabular}{|c|c|c|c|c|}
\hline \multirow{2}{*}{$\begin{array}{l}4 \overline{0} \\
+\frac{0}{0} \\
*\end{array}$} & \multicolumn{2}{|l|}{ Model specification } & \multirow{2}{*}{$\begin{array}{l}\text { Sample } \\
\text { size }\end{array}$} & \multirow{2}{*}{$\begin{array}{c}\text { Adj. } \\
R^{2}\end{array}$} \\
\hline & Linear model & Box-Cox transformation & & \\
\hline M2-1 & $Y=\underset{(6.8)}{0.961}-\underset{(-4.0)}{0.006} V_{85 a}+\underset{(14.7)}{0.0748} \sqrt{R_{1}}+\underset{(2.6)}{0.00055} L_{c 1}$ & $Y=1+\frac{\left(d_{95,2}+4\right)^{4.081}-1}{126.354}$ & 219 & 0.56 \\
\hline M2-2 & $Y=\underset{(11.6)}{1.347} \underset{(-5.8)}{0.006} 6 V_{85 a}+\underset{(19.0)}{0.0041} R_{1}+\underset{(11.4)}{0.00696} \omega_{1}$ & $Y=1+\frac{\left(d_{95,2}+4\right)^{2.565}-1}{14.549}$ & 111 & 0.77 \\
\hline M2-3 & $Y=\underset{(21.7)}{4.208} \underset{(-17.8)}{0.1485} R_{1}$ & $Y=1+\frac{\left(a_{95,2}\right)^{0.0532}-1}{0.07379}$ & 83 & 0.80 \\
\hline M3-1 & $Y=\underset{(36.8)}{2.718}-\underset{(-19.0)}{414.143} \frac{1}{R_{1}}$ & $Y=1+\frac{\left(a_{95,3}\right)^{-0.501}-1}{0.4365}$ & 162 & 0.69 \\
\hline M3-2 & $Y=\underset{(-16.6)}{-1.546}+\underset{(28.6)}{0.0117} R_{1}$ & $Y=1+\frac{\left(a_{95,3}\right)^{2.01}-1}{1.61054}$ & 52 & 0.94 \\
\hline M3-3 & $Y=\underset{(4.2)}{2.6444} \underset{(-15.3)}{0.006} R_{1}+\underset{(3.9)}{0.022} V_{85,3}$ & $Y=1+\frac{\left(a_{95,3}\right)^{0.728}-1}{0.6653}$ & 100 & 0.73 \\
\hline M4-1 & $d_{95,4}=1.00 \mathrm{~m} / \mathrm{s}^{2}$ & - & 301 & - \\
\hline M4-2 & $Y=\underset{(11.9)}{1.4442}+\underset{(13.1)}{0.00124} T_{L}-\underset{(-8.9)}{0.0133} V_{85,3}$ & $Y=1+\frac{\left(a_{95,4}\right)^{0.630}-1}{0.72633}$ & 71 & 0.75 \\
\hline
\end{tabular}




\begin{tabular}{|c|c|c|c|c|}
\hline \multirow{2}{*}{ 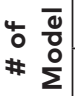 } & \multicolumn{2}{|l|}{ Model specification } & \multirow{2}{*}{$\begin{array}{l}\text { Sample } \\
\text { size }\end{array}$} & \multirow{2}{*}{ Adj. } \\
\hline & Linear model & Box-Cox transformation & & \\
\hline M4-3 & $Y=\underset{(-6.0)}{-1.925}+\underset{(9.0)}{0.00169} T_{L}+\underset{(4.2)}{0.011466} V_{85,3}$ & $Y=1+\frac{\left(a_{95,4}\right)^{0.570}-1}{0.6416}$ & 77 & 0.63 \\
\hline M6-1 & $Y=\underset{(27.3)}{4.220} \underset{(-11.0)}{0.01598} V_{85,5}-\underset{(-16.0)}{197.824} \frac{1}{R_{2}}$ & $Y=1+\frac{\left(d_{95,6}+4\right)^{2.661}-1}{18.1069}$ & 206 & 0.56 \\
\hline M6-2 & $Y=\underset{(-3.1)}{0.877}+\underset{(9.4)}{0.17935} \sqrt{R_{2}}$ & $Y=1+\frac{\left(d_{95,6}+4\right)^{4.484}-1}{7884.0621}$ & 82 & 0.51 \\
\hline M6-3 & $Y=\underset{(25.2)}{4.378}-\underset{(-7.1)}{0.0149} V_{85,5}-\underset{(-5.1)}{0.00035} T_{L}-\underset{(-12.1)}{709.975} \frac{1}{R_{2}}$ & $Y=1+\frac{\left(d_{95,6}+4\right)^{4.914}-1}{476.1505}$ & 123 & 0.67 \\
\hline M7-1 & $Y=\underset{(16.2)}{7.354}-\underset{(-14.6)}{0.0349} \omega_{2}-\underset{(-8.0)}{0.0351} V_{85,6}$ & $Y=1+\frac{\left(d_{95,7}+4\right)^{0.786}-1}{0.6573}$ & 173 & 0.56 \\
\hline M7-2 & $Y=\underset{(-10.5)}{-3.648}+\underset{(6.8)}{0.01576} \omega_{2}+\underset{(15.4)}{0.0603} V_{85,6}$ & $Y=1+\frac{\left(a_{95,7}\right)^{1.351}-1}{1.6743}$ & 137 & 0.72 \\
\hline M7-3 & $Y=\underset{(-15.9)}{-2.014}+\underset{(23.8)}{0.1335} \omega_{2}$ & $Y=1+\frac{\left(a_{95,7}\right)^{0.52}-1}{0.588}$ & 49 & 0.92 \\
\hline M8-1 & $Y=\underset{(18.7)}{4.764}-\underset{(-16.8)}{0.0257} \omega_{2}+\underset{(5.6)}{0.0143} V_{85,7}$ & $Y=1+\frac{\left(d_{95,8}+4\right)^{2.162}-1}{7.0210}$ & 176 & 0.62 \\
\hline M8-2 & $Y=\underset{(-7.3)}{-2.784}+\underset{(5.9)}{180.636} \frac{1}{R_{2}}+\underset{(10.0)}{0.0383} V_{85,7}$ & $Y=1+\frac{\left(a_{95,8}\right)^{-0.35}-1}{0.3214}$ & 131 & 0.44 \\
\hline M8-3 & $Y=\underset{(3.4)}{0.728}-\underset{(-9.3)}{0.00181} R_{2}+\underset{(5.4)}{0.01057} V_{85,7}$ & $Y=1+\frac{\left(a_{95,8}\right)^{-0.615}-1}{1.399}$ & 37 & 0.74 \\
\hline
\end{tabular}

included the cross sections of Curves 1 and 2 given in Figure 1. At the intermediate tangent, the results were not satisfactory because of the lack of fit. For this reason, it was decided to propose single values of acceleration for cross section 5, which are summarized in Table 7. The values were obtained superimposing the pdf of each range of geometrical values, obtaining a new pdf from which the $95^{\text {th }}$ percentile of acceleration and deceleration were estimated. 
Table 6 shows that in general the correlation of models is high, except for model M8-2. Also, in all models the Student $t$-values of each coefficient result are high enough to guarantee that the variables explain acceleration and deceleration. It can be noticed in Table 6 that both acceleration and deceleration are transformed according to Eq. (2).

The calibrated models permitted to visualize diverse behaviour patterns as a function of the HRC geometry: (a) in Curve 1, drivers decelerate when entering the curve and accelerate when departing the curves if radii are smaller than $400 \mathrm{~m}$; in case of larger radius, drivers accelerate; (b) in Curve 2 the behaviour is similar, but drivers start the acceleration manoeuvre at the middle point of the curve if the radius is smaller than $400 \mathrm{~m}$. In case of larger radius, drivers behave in the same manner in both curves; (c) the main variables that explain acceleration at the first curve of an HRC are the radius, the speed before each cross section, the curve length and the deflection angle. In addition to these variables, in Curve 2 the tangent length is also relevant for describing acceleration, particularly in the first part of the curve. For this reason, models such as those presented in Table 3 are not valid to study acceleration at the exit curve in an HRC; (d) Table 7 shows that in the HRC with short tangents and small exit radius, drivers decelerate along the tangent. On the contrary, if the HRC have long tangents, independently of the radius, drivers accelerate in the intermediate tangent.

The validation was tested using the $\chi^{2}$ statistical test, and the prognostic error indexes: Mean Square Error (MSE), Mean Absolute Error (MAE) and Mean Absolute Percent Error (MAPE). Table 8

Table 7. Acceleration and deceleration values proposed for the intermediate tangent

\begin{tabular}{|c|c|c|c|c|c|}
\hline$R_{1}, \mathrm{~m}$ & $L_{T}, \mathrm{~m}$ & $R_{2}, \mathrm{~m}$ & $a_{95,5}, \mathrm{~m} / \mathrm{s}^{2}$ & $d_{95,5}, \mathrm{~m} / \mathrm{s}^{2}$ & $\begin{array}{c}\text { Sample } \\
\text { size }\end{array}$ \\
\hline \multirow{3}{*}{$<200$} & $<200$ & $<200$ & & 1.17 & 5 \\
\hline & \multirow{2}{*}{$201-400$} & $<200$ & 0.88 & & 4 \\
\hline & & $201-400$ & 0.66 & & 3 \\
\hline \multirow{6}{*}{$201-400$} & $<200$ & $201-400$ & 0.67 & & 5 \\
\hline & & $<200$ & & 0.60 & 3 \\
\hline & $201-400$ & $201-400$ & 0.68 & & 4 \\
\hline & & $<200$ & & 0.66 & 2 \\
\hline & & $201-400$ & 0.73 & & 4 \\
\hline & $>400$ & $>400$ & 0.80 & & 4 \\
\hline$>400$ & $>400$ & $>400$ & 0.65 & & 5 \\
\hline
\end{tabular}


Table 8. Validation parameters of the models

\begin{tabular}{ccccccc}
\hline Model & Sample size & MSE, $\mathbf{m} / \mathbf{s}^{2}$ & MAE, $\mathbf{m} / \mathbf{s}^{2}$ & MAPE, $\%$ & $\chi^{2}$ estimated & $\chi^{2}$ critical \\
\hline M2-1 & 60 & 0.06 & 0.20 & 21.6 & -3.8 & 77.9 \\
M2-2 & 43 & 0.07 & 0.20 & 21.2 & -3.2 & 58.1 \\
M2-3 & 23 & 0.09 & 0.23 & 29.4 & +2.3 & 30.8 \\
M3-1 & 37 & 0.59 & 0.55 & 33.6 & +16.7 & 52.0 \\
M3-2 & 18 & 0.05 & 0.19 & 20.4 & +0.9 & 27.6 \\
M4-2 & 31 & 0.12 & 0.29 & 27.9 & +3.4 & 43.8 \\
M4-3 & 23 & 0.07 & 0.20 & 34.5 & +2.8 & 33.9 \\
M6-1 & 24 & 0.08 & 0.22 & 89.0 & +6.9 & 35.2 \\
M6-2 & 55 & 0.06 & 0.20 & 26.7 & -4.3 & 72.2 \\
M6-3 & 20 & 0.04 & 0.17 & 18.8 & -0.8 & 30.1 \\
M7-1 & 27 & 0.02 & 0.12 & 20.7 & -1.2 & 38.9 \\
M7-2 & 45 & 0.41 & 0.46 & 25.4 & -49.5 & 60.5 \\
M7-3 & 30 & 0.10 & 0.25 & 18.4 & +2.6 & 42.5 \\
M8-1 & 13 & 0.05 & 0.18 & 29.7 & +1.2 & 21.0 \\
M8-2 & 49 & 0.23 & 0.37 & 41.4 & -11.1 & 65.2 \\
M8-3 & 40 & 0.12 & 0.28 & 30.2 & +4.8 & 55.8 \\
\hline & 9 & 0.09 & 0.25 & 35.0 & +1.1 & 15.5 \\
\hline
\end{tabular}

shows the results obtained. Only model M4-1 and the models at the intermediate tangent were not validated, because these models are constant values. In all cases, the $\chi^{2}$ estimated was lower than the critical value of $\chi^{2}$, which means that the calibrated values and the observed values are statistically equal with a confidence level of $95 \%$. The highest dispersion was observed in the models at the middle point of Curve 1 for larger radius and in the middle point of Curve 2 for smaller radius. In the other models, the dispersion was significantly low.

\section{Conclusions}

This paper proposed acceleration/deceleration-geometry models for light cars in horizontal reverse curves. The model correlates with the $95^{\text {th }}$ percentile of the acceleration/deceleration pdf with geometrical parameters, such us radius, tangent length, and operative parameters, such as operating speed at the entrance tangent of the HRC. The model allows estimating point by point the acceleration/deceleration in the 
HRC, which allows obtaining better estimation of speed changes and the speed change length. Using these results, the developed model allows for better understanding of the acceleration/deceleration patterns and gives opportunity to enhance operating speed profiles of the HRC. In this context, the following conclusions were obtained.

The acceleration/deceleration fits with a Burr's pdf, which is asymmetrical. The results show that the lower percentiles of acceleration/deceleration are close to the median (approximately the $50^{\text {th }}$ percentile). On the contrary, the higher percentiles $\left(85^{\text {th }}\right.$ and $95^{\text {th }}$, for instance) are significantly different from the median. In addition, the analysis shows that the accelerations/decelerations estimated using kinematic equations are similar to the $50^{\text {th }}$ percentile. Therefore, the estimation of acceleration using kinematic equations estimates the lower values of acceleration/deceleration in the HRC. The practical consequence of using the $50^{\text {th }}$ percentile of acceleration/deceleration to model the speed profile of the HRC is present at the intermediate tangent. The use of low values of acceleration/deceleration induces underestimation of the maximum speed at the intermediate tangent affecting the precision of the speed profile.

The acceleration/deceleration pdf obtained were non-normal, asymmetrical and variable point-to-point in the HRC. Then, the assumptions of normality and homoscedasticity are violated, and the linear regression cannot to be used for modelling. To overcome this problem, the accelerations and decelerations were normalized with the Box-Cox transformation before calibrating the models. The acceleration/deceleration models were calibrated for all radius ranges and stratified by low and medium radius. In both cases, the adjusted correlation coefficient ranged between 0.44 and 0.94 . The validation obtained at the $95 \%$ confidence level was satisfactory too.

Only at the intermediate tangent the lack of fit of the models tested leads to proposing single values, which depend directly on the radius of both curves of the HRC and on the tangent length. This aspect needs a more detailed study to include other variables such as the available visibility or the driving style and its influence on the speed and acceleration.

The models obtained show that at each cross section of the HRC, the acceleration depends on the operating speed in the previous cross section and on the geometry of the next cross section. For this reason, it is preferable to use acceleration-geometry models rather than single values of acceleration or values stratified by the radius of each curve to estimate the speed profile of the HRC.

The acceleration/deceleration-geometry model proposed improves the estimation of the speed change in the operating speeds profiles, 
because it allows estimating the speed and acceleration point by point considering the HRC as a whole instead of estimating the speed changes with constant values considering the curves as isolate entities. This research contributed to improving the current procedures for statistical treatment of the accelerations/decelerations used in the state-of-the-art. In this sense, the identification of the actual pdf of these parameters allowed for precise definition of the "operating accelerations/decelerations".

\section{Acknowledgements}

The authors thank the National Fund for Scientific and Technological Development (FONDECYT) of the Ministry of Education of Chile for supporting the research project FONDECYT 1160128 "Operating speed models for passenger cars considering the effect of vertical alignment of two-lane rural roads", for which this paper was written.

\section{Disclosure Statement}

There are no financial conflicts of interest to disclose.

\section{REFERENCES}

Altamira, A., García, Y., Echaveguren, T., \& Marcet, J. (2014). Acceleration and deceleration patterns on horizontal curves and their tangents on two-lane rural roads. In Proc. of the 93rd Annual Meeting Transportation Research Board. United States, Washington, D.C., 12-16 January, 2014.

Arellano, D., Echaveguren, T., \& Vargas-Tejeda, S. (2015). A model of truck speed profiles on short upward slopes. In Proceedings of the ICE - Transport, 168(5), 475-483. https://doi.org/10.1680/tran.13.00012

Bella, F. (2013). Driver Performance Approaching and Departing Curves: Driving Simulator Studying. Traffic Injury Prevention, 15(3), 310-318. https://doi.org/10.1080/15389588.2013.813022

Crisman, B., Marchionna, A., Perco, P., Robba, A., \& Roberti, R. (2005). Operating speed prediction model for two-lane rural. In Proc. 3rd. International Symposium on Highway Geometric Design. United States, Chicago, 29 June to 2 July, 2005.

Crisman, B., Perco, P., Robba, A., \& Roberti, R. (2007). Deceleration model for two-lane rural roads. Advanced in Transportation Studies, 11, 19-32.

Dell'Acqua, G., Russo, F., Esposito, T., \& Lamberti, R. (2008). Accelerazione e decelerazione in curva: indagine sperimentale. [Acceleration and deceleration in curves: Experimental research]. In Proc of the 17th National
Longitudinal

Acceleration Models for Horizontal

Reverse Curves of Two-Lane Rural RoadsLanes of Road Intersections 
Conference SIIV. Italy, Enna, 10-12 September, 2008. Retrieved from: http:// www.siiv.it/Pubblicazioni/Atti di Convegni SIIV [Accessed on 10 September 2014].

Dell'Acqua, G., \& Russo, F. (2010). Speed factors on low-volume roads for horizontal curves and tangents. The Baltic Journal of Road and Bridge Engineering, 5(2), 89-97. https://doi.org/10.3846/bjrbe.2010.13

Echaveguren, T., \& Basualto, M. (2003). El análisis de aceleraciones en la consistencia de elementos simples de alineamientos horizontales. [Assessment of accelerations in the consistency of single elements of horizontal alignment]. In Proc of XI Chilean Conference on Transportation Engineering. Chile, Santiago, 20-24 October, 2003.

Echaveguren, T, Díaz, A., \& Vargas-Tejeda, S. (2015). Operating speed model for horizontal reverse curves. In Proceedings of the ICE - Transport, 169(6), 510-522. https://doi.org/10.1680/jtran.13.00016

FHWA. (2009). Manual of Uniform Traffic Control Devices for Streets and Highways. Washington D.C.: Federal Highway Administration. Retrieved from: https://mutcd.fhwa.dot.gov/kno_2009r1r2.htm

Figueroa, A., \& Tarko, A. (2007). Speed changes in the vicinity of horizontal curves on two-lane rural roads. Journal of Transportation Engineering, 133(4), 215-222. https://doi.org/10.1061/(asce)0733-947x(2007)133:4(215)

Fitzpatrick, K., \& Collins, J. M. (2000). Speed-profile model for two-lane rural highways. Transportation Research Record, 1737(1), 42-49.

https://doi.org/10.3141/1737-06

Fitzpatrick, K., Elefteriadou, L., Harwood, D., Collins, J., McFadden, J., Anderson, I., Krammes, R., Irizarry, N., Parma, K., Bauer, K., \& Passetti, K. (2001). Speed Prediction for two-lane rural highways. Report No. FHWA-RD-99-171, Federal Highway Administration, Washington D.C.

Hashim, I., Abdel-Wahed, T. A., \& Moustafa, Y. (2016). Toward an operating speed profile model for rural two-lane roads in Egypt. Journal of Traffic and Transportation Engineering, 3(1), 82-88. https://doi.org/10.1016/j.jtte.2015.09.005

Hu, W., \& Donnell, E. (2010). Models of acceleration and deceleration rates on a complex two-lane rural highway: results from a nighttime driving experiment. Transportation Research Part F: Traffic Psychology and Behaviour, 13(6), 397-408. https://doi.org/10.1016/j.trf.2010.06.005

Lamm, R., Beck, A., Ruscher, T., Mailaneder, T., Cafiso, S., \& La Cava, G. (2007). How to Make Two-lane Rural Roads Safer: Scientific Background and Guide for Practical Application. Southampton: WIT Press, 144 p. ISBN 1845641566

Montella, A., Pariota, L., Galante, F., Imbriani, L. L., \& Mauriello, F. (2014). Prediction of Drivers' Speed Behavior on Rural Motorways Based on an Instrumented Vehicle Study. Transportation Research Record, 2434, 52-62. https://doi.org/10.3141/2434-07

Park, Y.-J., \& Saccomanno, F. F. (2006). Evaluating speed consistency between successive elements of a two-lane rural highway. Transportation Research Part A: Police \& Practice, 40(5), 375-385.

https://doi.org/10.1016/j.tra.2005.08.003 
Perco, P., \& Robba, A. (2005). Evaluation of the deceleration rate for the operating speed-profile model. In Proc of the 3rd International SIIV Congress. Italy, Bari, 22-24 September. Retrieved from: http://www.siiv.it/ Pubblicazioni/Atti di Convegni SIIV [Accessed on 10 September 2014].

Pérez, A., García, A., Torregrosa, F., \& D’Attoma, P. (2010). Modeling operating speed and deceleration on two-lane rural roads with global positioning system data. Transportation Research Record, 2171, 11-20. https://doi.org/10.3141/2171-02

Pérez-Zuriaga, A., Camacho-Torregrosa, F. J., \& García, A. (2013). Tangent-to-Curve Transition on Two-Lane Rural Roads Based on Continuous Speed Profiles. Journal of Transportation Engineering, 139(11), 1048-1057. https://doi.org/10.1061/(asce)te.1943-5436.0000583

Xu, J., Lin, W., \& Shao, Y. (2017). New design method for horizontal alignment of complex mountain highways based on "trajectory-speed" collaborative decision. Advances in Mechanical Engineering, 9(4), 1-18. https://doi.org/10.1177/1687814017695437

Xu, J., Yang, K., \& Shao, Y. (2018). Ride Comfort of Passenger Cars on Two-Lane Mountain Highways Based on Tri-axial Acceleration from Field Driving Tests. International Journal of Civil Engineering, 16(3), 335-351.

https://doi.org/10.1007/s40999-016-0132-0
Longitudinal

Acceleration Models for Horizontal

Reverse Curves of Two-Lane Rural

RoadsLanes of Road Intersections 